\title{
Infantile Hemangioendothelioma of the Parotid Gland
}

\author{
Veeranna A. Kotrashettia, Vijay Baburao Sonawane ${ }^{\mathrm{a}, \mathrm{b}}$, Kapil Bainade ${ }^{\mathrm{a}}$, \\ Reshu Agarwal ${ }^{\mathrm{a}}$
}

\begin{abstract}
Tumors of salivary glands are uncommon in children (less than $5 \%$ ). Hemangioma is the commonest tumor of salivary gland tumors (more than $50 \%$ ). We report a rare case of infantile hemangioma $(\mathrm{IH})$ of parotid gland.
\end{abstract}

Keywords: Hemangioma; Hemangioendothelioma; Parotid gland

\section{Introduction}

Infantile hemangiomas (IHs) are the most common tumor of infancy and have a well-described natural history of rapid growth during early infancy followed by gradual involution $[1,2]$. Congenital capillary hemangioma is classified as true hemangioma of infancy [3]. It is usually not noticed in newborn period but becomes prominent in first months of life. Most common age of presentation is about 4 months. Parotid hemangioma demonstrates rapid growth in first months of life but usually regresses after 18 months [4]. MRI is the best imaging technique to demonstrate parotid hemangioma.

MRI shows hyperintense parotid gland hemangioma containing vascular flow voids. Ultrasonography (USG) Doppler demonstrates high vascularity and spectral blood flow.

\section{Case Report}

A two and half months old male infant presented with swelling in parotid gland since 15 days which was gradually increasing in size. Birth history was uneventful.

On local examination, swelling is present below left ear in

\section{Manuscript accepted for publication October 21, 2015}

${ }^{a}$ Department of Pediatrics, Dr. D. Y. Patil Medical College, Nerul, Navi Mumbai, India

${ }^{b}$ Corresponding Author: Vijay Baburao Sonawane, Department of Pediatrics, Dr. D. Y. Patil Medical College, Nerul, Navi Mumbai, India.

Email: vijay_ltm@yahoo.co.in parotid region, $4 \times 3 \mathrm{~cm}$ in size, smooth in surface, no pulsations with no signs of inflammation (Fig. 1).

Complete blood count was normal. USG revealed enlarged parotid gland measuring $3.1 \times 2.2 \times 2.5 \mathrm{~cm}$ with increased vascularity.

MRI showed well-defined, lobulated homogenously enhancing leison diffusely involving the superficial and deep layers of parotid gland (Fig. 2). Findings are suggestive of infantile hemangioendothelioma.

\section{Discussion}

IH of parotid gland is the most common tumor. Weiss and oth-

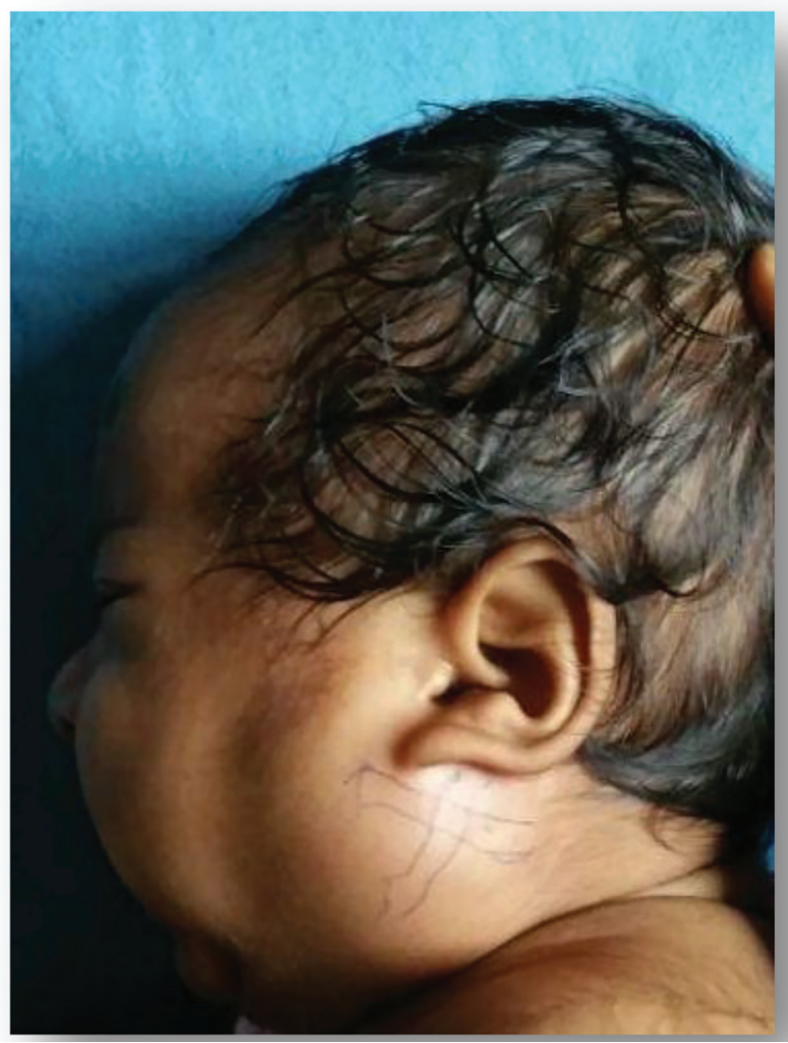

Figure 1. Swelling below left ear parotid gland. 


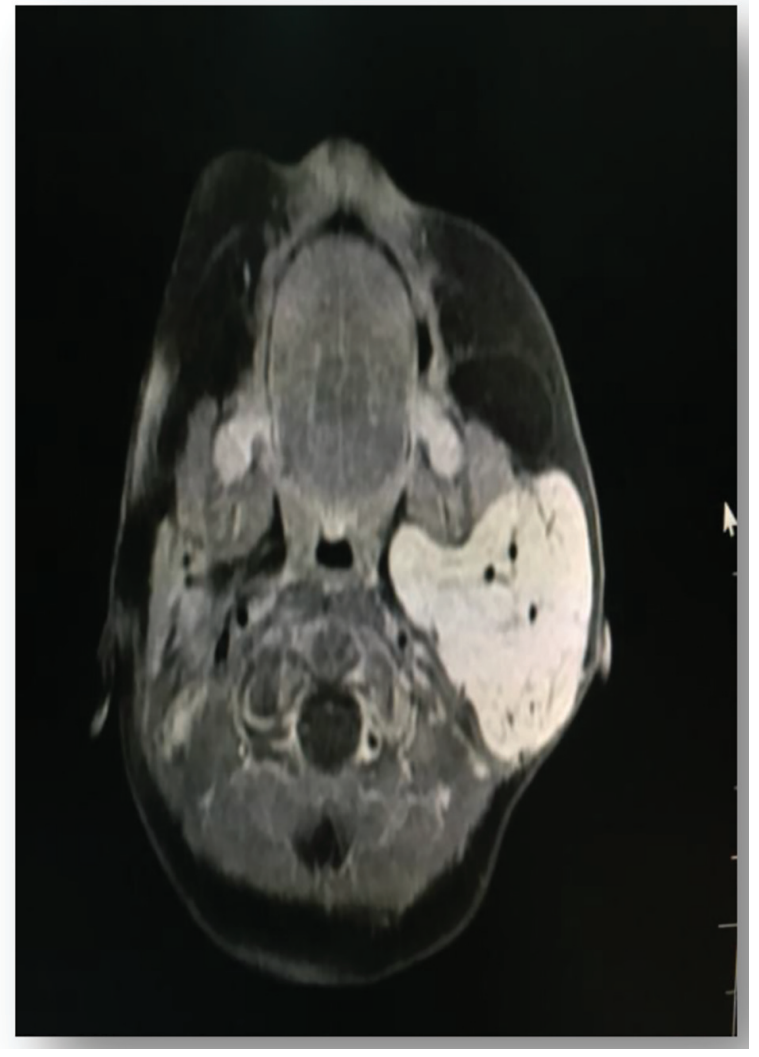

Figure 2. MRI findings suggestive of infantile hemangioendothelioma.

er presented 56 children with IH of parotid gland, 70\% being females [5]. Bluish or purple discoloration of overlying skin is a helpful clinical sign $[6,7]$. In our case, there was no change in color of the overlying skin.

$\mathrm{IH}$ is frequently seen at birth and grows fast during the first 6 months. In our case, the growth was seen after 2 months and it is gradually increasing in size. Clinical examination is usually diagnostic in IH. Imaging modalities are needed to confirm the diagnosis.

On USG, IHs are usually hyperechoic in relation to parotid tissue.

MRI helps in knowing the size and extent of the tumor in relation to adjacent structures.

$\mathrm{IH}$ in parotid gland can subside without treatment but rapid growth can produce cosmetic complications and others like ulceration, congestive cardiac failure and distortion of the adjacent structures. In our case, left parotid gland is replaced by the hemangioma.

Child was started on oral propanolol. Propanolol helps in vasoconstriction, decreased expression of vascular growth factors and activation of apoptosis of capillary endothelium cells [8].

Fuschman et al treated IH with propanolol in hemangiomas of various locations, and resulted in involution within 2 - 14 days [9].

In conclusion, $\mathrm{IH}$ is the commonest tumor of the parotid gland. It is presented in early life. It can be suspected on clinical grounds, but imaging studies are needed for the confirmation of diagnosis. Propanolol helps in reduction of $\mathrm{IH}$.

\section{References}

1. Brandling-Bennett HA, Metry DW, Baselga E, Lucky AW, Adams DM, Cordisco MR, Frieden IJ. Infantile hemangiomas with unusually prolonged growth phase: a case series. Arch Dermatol. 2008;144(12):1632-1637.

2. Haggstrom AN, Drolet BA, Baselga E, Chamlin SL, Garzon MC, Horii KA, Lucky AW, et al. Prospective study of infantile hemangiomas: clinical characteristics predicting complications and treatment. Pediatrics. 2006;118(3):882887.

3. Som P, Curtin HD. Head and neck imaging, 4th edition. Vol 2. St Louis: mos by. 2002: 1852-2185.

4. Bruyn R. Pediatric ultrasonography. Tunaci A, Yekeler E, Trans Eds. Pediatric Ultrason. Istanbul Medikal; 2007; p. 287-289.

5. Weiss I, O TM, Lipari BA, Meyer L, Berenstein A, Waner $\mathrm{M}$. Current treatment of parotid hemangiomas. Laryngoscope. 2011;121(8):1642-1650.

6. Goldman RL, Perzik SL. Infantile hemangioma of the parotid gland; a clinicopathological study of 15 cases. Arch Otolaryngol. 1969;90(5):605-608.

7. Takato T, Komuro Y, Yonehara Y. Giant hemangioma of the parotid gland associated with Kasabach-Merritt syndrome: a case report. J Oral Maxillofac Surg. 1993;51(4):425-428.

8. Leaute-Labreze C, Dumas de la Roque E, Hubiche T, Boralevi F, Thambo JB, Taieb A. Propranolol for severe hemangiomas of infancy. N Engl J Med. 2008;358(24):26492651.

9. Fuchsmann C, Quintal MC, Giguere C, Ayari-Khalfallah S, Guibaud L, Powell J, McCone C, et al. Propranolol as first-line treatment of head and neck hemangiomas. Arch Otolaryngol Head Neck Surg. 2011;137(5):471-478. 